\title{
Dermatologist Contribution to Early Detection and Management of the Precancerous Lesions (PCL) of the Cervix in HIV Positive Patients: A Study in a Country with Limited Resources
}

\section{Sangaré Abdoulaye ${ }^{1 *}$, Ecra Elidjé Joseph ${ }^{1}$, Guié Privat ${ }^{2}, K_{\text {Kouroumah Sarah Hamdan }}^{1}$, Kaloga Mamadou$^{1}$, Gbery lldevert Patrice ${ }^{1}$, Anoh N} Joachim ${ }^{1}$ and Touré Coulibaly Kady ${ }^{2}$

${ }^{1}$ Department of Dermatology, University Hospital of Treichville, Republic of Côte d'ivoire

${ }^{2}$ Department of Obstetric Gynecology, University Hospital of Treichville, Republic of Côte d'ivoire

\section{Abstract}

Purpose: In recent years, some authors have reported a high prevalence of cervical cancer in HIV depressed patients. As our unit also aims to protect HIV-positive patients of all diseases or all opportunist infections it was found appropriate to conduct this study in order to contribute to the early detection of precancerous lesions of the cervix (LPC) using the VIA technique with our patients.

Methods: This study which is a longitudinal prospective one was conducted in a descriptive and analytical perspective. It was carried out within the voluntary testing centre (VTC) of the Department of Dermato-Venereology of the University Hospital of Treichville and in collaboration with the Department of Gynecology. The recruitment of patients was done within a 4-month-period using a survey form. The study included 150 women screened HIV+ under anti-retroviral treatment (ARV) within the VTC. They were followed up at 4-month intervals. They were aged 18 or upper. They agreed to participate in this study on a verbal consent basis. None of them were commercial sex workers.

Results: Demographics of PLWHA in our study were similar to those observed in the literature;

-16/150 women had a positive VIA test (10.6\%);

- The factors favoring the occurrence of cervical PCL in our study were:

- $\quad$ Age of the first sexual intercourse;

- $\quad$ The existence of vulvar warts, genital herpes and a cervicovaginitis;

- $\quad$ CD4 level $<200 / \mathrm{mm}^{3}$

Conclusion: The cancer of the cervix as a concern for any woman is also a concern for those living with HIV. Its real extent in women infected with HIV is still unknown in our country because large scale screening is not conducted given financial difficulties. We believe that the method of detection of PCL using VIA technique should be encouraged because of its affordability in a limited resource countries of ours.

Keywords: Screening; PCL; Cervix; VIA; PLHIV

Abbreviations: ARV: Anti Retroviral; VCT: Voluntary Testing Centre; CECAP: Cervical Cancer Prevention; CHU: Hospitalo Centre Universitaire; FCV: Pap smear; IVA: Visual inspection with acetic acid; JHPIEGO: NGOs Johns Hopkins International Education for Gynecologics Obstetrics; LPC: Pre-Cancerous Lesions; PLWHA: People Living with Human Immunodeficiency Virus; HIV: Human Immunodeficiency Virus

\section{Introduction}

The cancer of the cervix is a tissue neo-formation due to excessive cell proliferation, uncontrolled and autonomous, leading to the destruction of the cervix with local invasion and distant [1].

Pathology considered as a serious public health problem, the cervix cancer is the first cause of death in women in many countries with limited resources. In our country, the mortality rate associated with this type of cancer is $11.1 \%$ [2].

If in industrialized countries, morbidity and mortality is relatively low because of the abundance of medical equipments and the extension of screening, it is not the case in developing countries where poverty and precariousness impede screening [3]. The occurrence of cervical cancer could be regarded as negligence from patients; but also from any health agent as clinical examination of any woman we receive should be completed by the examination of the cervix.

Additionally, the cervical smear (CS) which is the examination technique mostly used in our country for screening cervical cancer is unfortunately very expensive for extensive screening. However, there is a simple, effective method of screening for precancerous lesions of the cervix approved by WHO since 1985 which consists in the visual inspection of the cervix after brushing with acetic acid (VIA) [4].

*Corresponding author: Abdoulaye Sangare, Department of Dermatology, University Hospital of Treichville, P.O. Box: 408 cidex Abidjan, Republic of Côte d'ivoire, Tel: 00225 22008998; E-mail: sang abdoulaye@yahoo.fr

Received December 03, 2013; Accepted February 20, 2014; Published March 02,2014

Citation: Abdoulaye S, Joseph EE, Privat G, Hamdan KS, Mamadou K, Patrice $\mathrm{Gl}$, et al. (2014) Dermatologist Contribution to Early Detection and Management of the Precancerous Lesions (PCL) of the Cervix in HIV Positive Patients: A Study in a Country with Limited Resources. J AIDS Clin Res 5: 287. doi:10.4172/21556113.1000287

Copyright: (c) 2014 Abdoulaye S, et al. This is an open-access article distributed under the terms of the Creative Commons Attribution License, which permits unrestricted use, distribution, and reproduction in any medium, provided the original author and source are credited. 
In recent years, some authors have reported a high prevalence of cervical cancer in HIV depressed patients. As our Unit's duty is also to protect HIV-positive patients against all diseases or all opportunist infections it was found appropriate to conduct this study in order to contribute to the early detection of precancerous lesions of the cervix (PCL) using the VIA technique with our patients.

Specifically, our task consisted in: 1) identifying the sociodemographic characteristics of our study population to determine the prevalence of precancerous lesions (PCL) of the cervix in women; 2) identifying risk factors of occurrence of cervical PCL; and 3) indicating PCL therapeutic modalities in PLWHA.

\section{Material and Methods}

The study was conducted within the unit of the voluntary testing center (VCT). The VCT is a service specialized in the detection of AIDS and also in monitoring HIV patients. It is integrated to the Dermatology and Venereology Department. Dermato-venereologists in our country do not only take care of skin illnesses. They are trained to treat sexually transmitted illnesses (STIs) and are therefore accustomed to gynecological examinations in their daily practice.

This work was carried out in collaboration with the gynecologic unit of the same university hospital. It is part of CECAP (Cervical Cancer Prevention) project that currently supports the organization and implementation of screening activity of precancerous lesions of the cervix in Côte d'Ivoire. The CECAP which is itself a partner of JHPIEGO is the structure that provided us with acetic acid.

This study which is a longitudinal prospective one was conducted in a descriptive and analytical perspective. It was carried out within the voluntary testing centre (VTC) of the Department of DermatoVenereology of the University Hospital of Treichville and in collaboration with the Department of Gynecology. The recruitment of patients was done within a 4-month-period using a survey form. The study included 150 women screened HIV+ under anti-retroviral treatment (ARV) within the VTC. They were followed up at 4-month intervals. They were aged 18 or upper. They agreed to participate in this study on a verbal consent basis. None of them were commercial sex workers.

However, were excluded from the study patients with a lower age of 18 , due to difficulties in obtaining verbal consent from them. Women over 7-month pregnancy were also excluded to avoid any risk of uterine contractions.

For all women included in the study, a series of examination was done including the determination of CD4 level and a vaginal swab with microbiological examination. A week later, when the women returned with the results of various examinations, we took advantage to carry out the VIA test. It consisted in applying to the cervix acetic acid or lugol (Schiller's test) during gynecological examination. In case of abnormality any tissue on the cervix whitened and thus became visible. Yet, no biopsy of the cervix was performed in these women.

The VIA test was declared negative if it appeared bleaching (acidophilus zone) away from the squamo-columnar junction area (exo-endocervical junction area, meaning malignant transformation).

On the contrary, in case of suspicious precancerous lesions or invasive cancer, the application of acetic acid resulted in the bleaching of the squamo-columnar junction area (see Iconography; Figure 1). When the VIA test was found positive, all suspicious areas whose size was less than or equal to $5 \mathrm{~cm}$ were immediately taken care of in the department

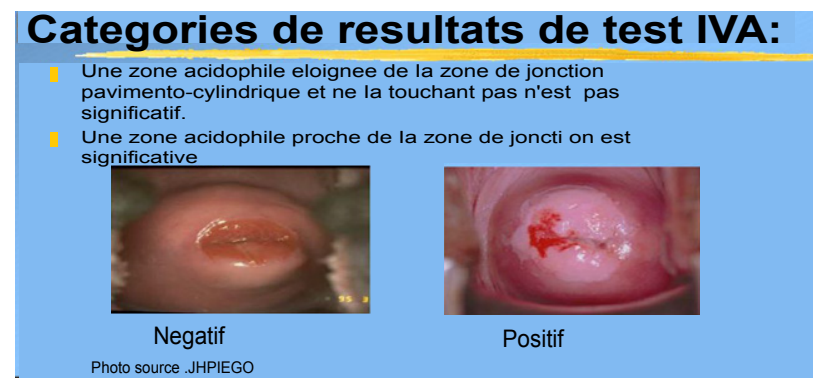

Figure 1: Iconographie 1: Résultats de l'IVA Source: JHPIEGO Photo store.

of dermatology through the method of cryotherapy. However, the large lesions that could not be treated with cryotherapy were addressed to the gynecology department for proper care.

The parameters studied were:

- Socio demographic characteristics of PLWHA;

- The prevalence of PCL in PLHIV;

- The risk factors for cervical PCL PLHIV;

- And the recommended treatment for PCL cervix.

The recording, processing and data analysis were made on the PC using the EPI INFO software, Version 6.04d. The statistical tests used were Pearson Chi square test or Fisher's exact test with $\mathrm{P}$ value corresponding to a significance level of $<0.05$.

\section{Results}

\section{Socio-demographic clinical, para-clinical characteristics of patients and risk factors for cervical PCL (Table 1)}

The average age was 37.5 years. The youngest patient was 18 and the oldest 57 years old. The socioeconomic status was assessed by monthly income. The minimum wage in this country is about 37,000 FCFA (U.S. $\$ 74)$. And are considered to have low socioeconomic status, subjects whose monthly income was less than 50.000FCFA (100 U.S. dollars). They were $118 / 150$ in number (or $78.6 \%$ of PLHIV). The socioeconomic average was constituted by PLHIV with a monthly income between 100 and 250.000FCFA (200 and 500 U.S. dollars). They were 32/150 in number (or 21.4\%).

For marital status, singles represented $70.6 \%$ of PLHIV (106/150). For parity, it was identified $84 / 150$ or $56 \%$ multiparous. 101 PLHIV reported having their first sexual intercourse after 18 years (67\%). 83 PLHIV said they had only one sexual partner (55\%). On clinical examination, we found in 12/150 PLHIV (8\%) vulvar warts and 3 cases of genital herpes $(2 \%)$.

Serological level, $147 / 150$ were screened HIV1 or $98 \%$ and $99 / 150$ PLHIV (66\%) had a CD4 rate greater than $200 / \mathrm{mm}^{3}$. Finally, the vaginal swab with microbiological examination had identified 25/150 cases of cervico-vaginitis (16.6\%).

\section{Prevalence of LPC cervix and risk factors among PLHIV}

Of the 150 PLHIV who verbally agreed to participate in the study, 16 were positive for VIA test (prevalence 10.6\%). There was no difference between the two compared groups (positive and negative VIA) for age, socioeconomic level, marital status, multi-pregnancy and HIV serotype. However, the age of first sexual intercourse, the presence of 
Citation: Abdoulaye S, Joseph EE, Privat G, Hamdan KS, Mamadou K, Patrice GI, et al. (2014) Dermatologist Contribution to Early Detection and Management of the Precancerous Lesions (PCL) of the Cervix in HIV Positive Patients: A Study in a Country with Limited Resources. J AIDS Clin Res 5: 287. doi:10.4172/2155-6113.1000287

Page 3 of 4

\begin{tabular}{|c|c|c|c|}
\hline \multirow{2}{*}{ Features } & \multicolumn{2}{|l|}{ VIA Test } & \multirow{2}{*}{ Value $\mathrm{P}$} \\
\hline & Positive $(\mathrm{N}=16)$ & Negative $(N=134)$ & \\
\hline \multicolumn{4}{|l|}{ Age in years } \\
\hline $18-49$ & $1275 \%$ & $11988.8 \%$ & \\
\hline$\geq 50$ & $0425 \%$ & $1511.2 \%$ & 0.11 \\
\hline \multicolumn{4}{|l|}{ Socio-economic level } \\
\hline Middle & $0212.5 \%$ & $3022.3 \%$ & \\
\hline Low & $1487.5 \%$ & $10477.3 \%$ & 0.55 \\
\hline \multicolumn{4}{|l|}{ Marital status } \\
\hline Married & $0425 \%$ & $4029.8 \%$ & \\
\hline Single & $1275 \%$ & $9470.2 \%$ & 0.91 \\
\hline \multicolumn{4}{|l|}{ Parity } \\
\hline Multi-pares & $0743.7 \%$ & $7757.4 \%$ & \\
\hline Mono-parity & $0956.3 \%$ & $5742.6 \%$ & 0.29 \\
\hline \multicolumn{4}{|c|}{ Age of first sexual intercourse } \\
\hline Below 18 & $1275 \%$ & $3727.6 \%$ & \\
\hline$\geq 18$ & $0425 \%$ & $9763.4 \%$ & 0.001 \\
\hline \multicolumn{4}{|c|}{ Number of sexual partner } \\
\hline Single partner & $0425 \%$ & $7955.9 \%$ & \\
\hline Multi-partner & $1275 \%$ & $5541.1 \%$ & 0.009 \\
\hline \multicolumn{4}{|c|}{ Existence or not of a vulvar condyloma } \\
\hline Yes & $0531.2 \%$ & $075.2 \%$ & 0.00 \\
\hline Non & $1168.8 \%$ & $12794.8 \%$ & \\
\hline \multicolumn{4}{|c|}{ Existence or not of another STI } \\
\hline Cervico-vaginitis & $0743.5 \%$ & $1813.4 \%$ & 0.00 \\
\hline Genital herpes & $0318.7 \%$ & 00 & \\
\hline No STI & $0637.5 \%$ & $11686.5 \%$ & \\
\hline \multicolumn{4}{|l|}{ HIV serotype } \\
\hline HIV 1 & $16100 \%$ & $13197.7 \%$ & \\
\hline $\mathrm{VIH} 2$ & 00 & $032.3 \%$ & 0.73 \\
\hline \multicolumn{4}{|l|}{ CD4 rate } \\
\hline Below $200 / \mathrm{mm}^{3}$ & $0956.2 \%$ & $4231.2 \%$ & 0.04 \\
\hline$\geq 200 / \mathrm{mm}^{3}$ & $0743.8 \%$ & $9268.8 \%$ & \\
\hline
\end{tabular}

Table 1: : Epidemiological, clinical and serological characteristics by testing the VIA.

vulvar warts and genital herpes, the existence of a cervico-vaginitis and a CD4 rate below $200 / \mathrm{mm} 3$ were significantly associated with positive VIA test (P inferior to 0.005).

\section{Treatments}

We treated 12/16 patients. Four quitted the follow-up before the study was completed. Among the twelve remaining patients treated, nine $(75 \%)$ were eligible for cryotherapy. Three patients among the twelve were taken care of within the dermatologist department using the Loop Electro Excision Procedure (LEEP) as the latter exhibited large suspicious lesions.

\section{Discussions}

It has been recognized for some years that the occurrence of cervical PCL would be more frequent and faster in PLHIVs [5-9]. Yet, it is a cancer that can be prevented by early detecting precancerous lesions for treatment.
In developed countries, screening programs have been implemented to detect and treat

PCL early. These programs are generally based on the cervicovaginal smear screening followed by colposcopy and biopsy when indicated [10]. Such programs are so expensive that their applicability abuts the financial difficulties faced by developing countries. However, it is possible that every woman in the world has the right to prevention in the light of tools available. This is one of the reasons why the administrative authorities provided our voluntary testing centers for HIV with VIA equipments. Usually restricted to gynecologists, the VIA technique will revolutionize screening campaigns for precancerous cervical lesions because it is a simpler, less expensive technique and that can be applied by any health professional if well trained [4]. The major drawback of this method is that it results in PCL over diagnosis. The results of our work though preliminary led us to make some comments on some aspects observed in our service.

The socio-demographic characteristics of our study population are somewhat different from characteristics already reported by various studies [11].

Among these 150 PLHIVs, 16 patients had a positive VIA test, a prevalence of $10.6 \%$ (cf. Table 1). This prevalence seems to be underestimated and especially as neoplasia cervical intraepithelial are asymptomatic lesions. Only systematic mass screening in all women at reproductive age sexual activity, could give a true prevalence. We will here encourage all practitioners and especially the National Program for the Fight against AIDS (NPA) to include if possible the VIA test in monitoring of PLHIVs. Research on predisposing factors was made taking into account the characteristics studied.

Thus, epidemiologically, regarding the age bracket $18-49,12$ patients (75\%) had a positive VIA test. If for some authors, cervical dysplasias are strongly related to age and experience usually peaks in early sexual activity until the age of 30-35 [12], for others, no age bracket is more susceptible than the other. According to these authors, any woman who has sexual activity is susceptible to develop cervical PCL [11].

Over $85 \%$ of PLHIVs with a positive VIA test had a low socioeconomic level $(\mathrm{P}=0.55)$ (cf. Table 1). This breakdown by socioeconomic level in our work is not significant and is due to chance. This could be explained by the fact that in our context most of patients who attend public hospitals are deprived persons unable to attend private clinics. However, for some authors, lower social class could contribute to the occurrence of cervical cancer because lower class would subsume low level of education, nutritional deficiency, recurrent genital infections and limited access to information that are considered all as predisposing factors [13].

Marital status in PLHIVs with a positive VIA test was dominated by single $(75 \%)(\mathrm{P}=0.91)$ (cf. Table 1$)$. If being single is not directly linked to the occurrence of cervical PCL, it predisposes in case of sex with multiple partners. This multi sexual partner was found in $3 / 4$ patients $(75 \%)$ with a positive VIA test $(\mathrm{P}=0.009)$. For some authors, the more sexual activity is common and varied in young women the more risk of occurrence of various cervical lesions is greater [2].

The multiparous was found in $43.7 \%$ of PLHIVs with a positive VIA test (cf. Table 1). This distribution in our study was not significant. However, multipares is regarded as contributing factor in the occurrence of cervical PCL. Indeed, for many authors, the prevalence of HPV infection is a key element in the development of cervical PCL is higher during pregnancy because of the stimulating effect of progesterone on 
Citation: Abdoulaye S, Joseph EE, Privat G, Hamdan KS, Mamadou K, Patrice GI, et al. (2014) Dermatologist Contribution to Early Detection and Management of the Precancerous Lesions (PCL) of the Cervix in HIV Positive Patients: A Study in a Country with Limited Resources. J AIDS Clin Res 5: 287. doi:10.4172/2155-6113.1000287

Page 4 of 4

the replication virus or due to the decrease in cellular immunity in these pregnant women [14].

Three out of four patients (75\%) with a positive VIA test had their first sexual intercourse before age 18 (cf. Table 1). This early sexual activity is a contributing factor to the occurrence of PCL in our work $(\mathrm{P}=0.001)$. Indeed, young subjects have sexual carefree activity and very often without any protection. Whereas, it is well known that sexual behavior is the main risk for STIs, some of which are known as cofactors predisposing to PCL [11].

Clinical examination and vaginal swabs with microbiological examination had identified the presence of certain sexually transmitted infections (STIs) among PLHIVs with a positive VIA test. Thus, we found $31.2 \%$ of vulvar warts, $43.5 \%$ of cervico-vaginitis and $18.7 \%$ of genital herpes (cf. Table 1). For all these STIs, P value calculated was $0.00 \%$ and this showed that there was indeed a correlation between the occurrence of STIs and cervical PCL. Thus, HPV infection is a factor implicated in the occurrence of PCL. For some authors, the risk of developing CIN is higher among PLHIV in case of oncogenic HPV infection because of its persistence in this field [2]. These HPV would act as cofactors in the genesis of cervical PCL [15]. As far as the cervicovaginitis $(43.5 \%)$ and genital herpes $(18.7 \%)$ are concerned, it is their inflammatory action that weakens the cervix and makes it permeable to HPV [12]. These sexually transmitted illnesses (STIs) recognized as cofactors in PCL are cervical pathologies treated in our practice as Dermatologist. This means that the importance of the dermatologist up streams in the fight against cervical cancer by an adequate management of all STIs.

Immunological data have allowed us to note that $100 \%$ of PLHIVs with a positive VIA test were positive for HIV 1 and CD4 rate in these patients was $56.2 \%$ less than $200 \mathrm{~mm}^{3}$ (cf. Table 1 ). The HIV 1 serology observed in $100 \%$ of PLHIVs is the serotype most often observed. However, the occurrence of cervical PCL is coincidental and is not tied to a particular serotype $(\mathrm{P}=0.73)$.

If the HIV serotype does not influence the occurrence of cervical cancer, the study showed that a low CD4 rate was however, a factor favoring the occurrence of cervical PCL in PLHIVs $(\mathrm{P}=0.04)$. Indeed, the low rate of $\mathrm{CD} 4$ results in a critical decrease of immunity thus exposing patients to other viral infections namely the papilloma virus [14,16-18].

Similarly, we know that the elimination of these HPV depends on the clearance which itself depends on the cellular immunity of the host. If the withdrawal of HPV non oncogenic from the body of is faster, it is not the case for oncogenic HPV whose elimination is very slow due to immune-depression. It is this persistence of HPV that will be the main risk factor for subsequent development of pre-invasive and invasive lesions of the cervix on this field [19,20].

Finally, at the therapeutic level, the cryotherapy was the method we used to deal with suspicious lesions of small size in $75 \%$ of patients. The VIA is an asset which allows to view suspicious lesions, but it allows at the same time to treat them. The effectiveness of this treatment was assessed during previous visits by patients without suspicious area on the cervix after new applications of acetic acid. However, for large lesions which are out of the competence of the dermatologist were oriented to the Department of Gynecology for treatment by electro surgical excision procedure or LEEP (Loop Electro Excision Procedure).

\section{Conclusion}

The cancer of the cervix as a concern for any woman is also a concern for those living with HIV. Its real extent in women infected with HIV is still unknown in our country because large scale screening is not conducted given financial difficulties. We believe that the method of detection of PCL using VIA technique should be encouraged because of its affordability in a limited resource countries of ours.

\section{References}

1. Baldoul JJ, Hamed D, Riter Y, Walter $P$ (2003) Néoplasies intra épithéliale du col utérin. Encycl Med, Elsevier Paris-Gynécologie 597-A-10, 20.

2. La Ruche G, You B, Mensah-Ado I, Bergeron C, Montcho C, et al. (1998) Human papillomavirus and human immunodeficiency virus infections: relation with cervical dysplasia-neoplasia in African women. Int J Cancer 76: 480-486.

3. Ba HY (2002) Cancer invasive du col utérin chez la femme à sérologie VIH positif. Caractéristiques cliniques et paracliniqtues. Thèse Med Abidjan No. 313194.

4. Dalstein V, Riethmuller D, Prétet JL, Le Bail Carval K, Sautière JL, et al. (2003) Persistence and load of high-risk HPV are predictors for development of highgrade cervical lesions: a longitudinal French cohort study. Int J Cancer 106: 396-403.

5. Boulanger JC, Naepels $P$ (2001) [Screening and diagnosis of cervical cancer] Rev Prat 51: 1426-1431.

6. Sobesky M, Marty CH Six G, Vincenzi I, Pradinaud R (1999) Influence de l'infection par le VIH sur les lésions dysplasiques du col utérin en Guyanne française. Rev Fr gynecol obstet 94: 11-16.

7. Gaffikin L, Lauterbach M, Blumenthal PD (2003) Performance of visua inspection with acetic acid for cervical cancer screening: a qualitative summary of evidence to date. Obstet Gynecol Surv 58: 543-550.

8. Odafe S, Torpey K, Khamofu H, Oladele E, Adedokun O, et al. (2013) Integrating cervical cancer screening with HIV care in a district hospital in Abuja, Nigeria. Niger Med J 54: 176-184.

9. Ahr A, Scharl A, Lütke K, Staszewski S, Kacer PZ, et al. (2000) Cervical intraepithelial neoplasia in human immunodeficiency virus-positive patients. Cancer Detect Prev 24: 179-185.

10. Cardillo M, Hagan R, Abadi J (2001) CD4 T cell count, viral load and squamous intraepithelial lesions in women infected with the human immunodeficicency virus. Cancer 93: 111-114.

11. Nkegoum B, Belley Priso E, Mbakop A, Gwent Bell E (2001) [Precancerous lesions of the uterine cervix in cameroonian women. Cytological and epidemiological aspects of 946 cases]. Gynecol Obstet Fertil 29: 15-20.

12. Vacher-Lavenu MC (2001) [Histology and cytology of cervical cancers]. Rev Prat 51: 1417-1423.

13. Ellerbrock TV, Chiasson MA, Bush TJ, Sun XW, Sawo D, et al. (2000) Incidence of cervical squamous intraepithelial lesions in HIV-infected women. JAMA 283: 1031-1037.

14. Riethmuller D, Schaal JP, Mougin C (2002) [Epidemiology and natural history of genital infection by human papillomavirus]. Gynecol Obstet Fertil 30: 139-146.

15. Ferrero S, Arena E, De Masi E, Biasotti B, Fulcheri E, et al. (2002) Screening and treatment for cervical intraepithelial neoplasia (CIN) in HIV-infected women. Minerva Ginecol 54: 297-307.

16. Peko JF, Buambo S, Diafouka M, Nsonde J, Ngolet A (2009) Lésions précancéreuses du col utérin et infection VIH à Brazzaville. Med AF. Noire No. 5610: 532-536.

17. Ouattara S, Some DA, Bambara M, Dao B (2009) Cancer du col et VIH en Afrique. Journ Afr du cancer 1: 110-114.

18. Lomalisa P, Smith T, Guidozzi F (2000) Human immunodeficiency virus infection and invasive cervical cancer in South Africa. Gynecol Oncol 77: 460-463.

19. Mougin C, Dalstein V, Prétet JL, Gay C, Schaal JP, et al. (2001) [Epidemiology of cervical papillomavirus infections. Recent knowledge]. Presse Med 30 1017-1023.

20. Sevcík L, Koliba P, Konderla M, Gráf P, Hlavacka J (2003) [Human papillomavirus infection and cervical intraepithelial neoplasia]. Ceska Gynekol 68: 237-243. 